\title{
HUBUNGAN PARITAS DAN FUNGSI PEMANFAATAN BUKU KIA DENGAN PENGETAHUAN IBU HAMIL TENTANG TANDA BAHAYA KEHAMILAN DI WILAYAH KERJA PUSKESMAS MARTAPURA 2 KABUPATEN BANJAR
}

\author{
(The Correlation of Parity and The Function of Kia Books Utilization \\ With The Knowledge of Pregnant Women About The Danger \\ Signs of Pregnancy at The Working Area of Martapura 2 \\ Primary Healthcare In Banjar District)
}

\author{
Siska Dhewi, A. Zacky Anwary, Septi Anggraeni \\ Fakultas Kesehatan Masyarakat UNISKA MAB \\ Email : siskadhewi1987@gmail.com
}

\begin{abstract}
ABSTRAK
Berdasarkan data Kementerian Kesehatan Republik Indonesia (Kemenkes RI), Angka Kematian Ibu (AKI) pada tahun 2015 masih sangat tinggi yaitu 305/100.000 kelahiran hidup. Diantara penyebabnya adalah keterlambatan mengetahui risiko atau tanda bahaya kehamilan. Tujuan penelitian ini untuk mengetahui hubungan fungsi pemanfaatan buku KIA dengan pengetahuan ibu hamil tentang tanda bahaya kehamilan di Wilayah Kerja Puskesmas Martapura 2 Kabupaten Banjar. Menggunakan metode analitik kuantitatif dengan rancangan cross sectional pada responden yang terdiri dari 83 ibu hamil. Hasil penelitian menunjukan bahwa ada hubungan antara paritas dengan pengetahuan ibu hamil dengan nilai $p=0,027$, terdapat hubungan antara fungsi pencatatan buku KIA dengan pengetahuan ibu hamil $(p=0,012)$ dan variabel fungsi komunikasi buku KIA berhubungan dengan pengetahuan ibu hamil $(p=0,038)$. Direkomendasikan bagi Pihak Puskesmas agar meningkatkan fungsi pemanfaatan buku KIA dengan membuat kebijakan untuk mewajibkan ibu hamil membaca buku KIA sebelum mendapatkan pelayanan ANC.
\end{abstract}

Kata Kunci : Fungsi Pemanfaatan buku KIA, Paritas, Pengetahuan Ibu Hamil

\section{ABSTRACT}

Based on data from the Ministry of Health (Indonesia), the Maternal Mortality Rate (MMR) in 2015 is still very high at 305 / 100,000 live births. Among the causes are delays in knowing the danger signs of pregnancy. The purpose of this study was to determine the relationship of the function of KIA books utilization with the knowledge of pregnant women about the danger signs of pregnancy in the Work Area of Martapura 2 Public Health Center, Banjar Regency. Using quantitative analytical methods with cross sectional design on respondents consisting of 83 pregnant women. The results showed that there was a relationship between parity and knowledge of pregnant women with a value of $p=0.027$, there was a relationship between the function of recording KIA book with knowledge of pregnant women $(p=0.012)$ and communication functions of KIA book related to the knowledge of pregnant women $(p=0.038)$. It is recommended for Primary Healthcare to improve the function of utilizing KIA book by making a policy to require pregnant women to read KIA books before getting ANC services.

Keywords: Knowledge of Pregnant Women, Function of KIA books Utilization, Parity

\section{PENDAHULUAN}

Angka Kematian Ibu (AKI) dibeberapa Negara berkembang disebabkan saat proses kehamilan, persalinan dan nifas yang merupakan masalah komplek dan berkepanjangan. Bahkan 
sampai saat ini masalah tersebut belum teratasi.Dinegara miskin, sekitar 25-50\% kematian wanita subur disebabkan oleh hal yang berkaitan dengan kehamilan.Kematian saat melahirkan biasanya menjadi faktor utama mortalitas wanita muda pada masa puncak produktivitas (Saifuddin, 2006).

Menurut data World Health Organization (WHO) menjelaskan bahwa pada tahun 2005 sebanyak 536.000 perempuan meninggal dunia akibat persalinan. Angka Kematian Ibu (AKI) dan Angka Kematian Bayi (AKB) di Indonesia masih tinggi dibandingkan dengan negara ASEAN. AKI di Indonesia pada tahun 2016 ada 305 / 100.000 kelahiran hidup, dan Angka Kematian Bayi 25,5 / 1000 kelahirn hidup.

Salah satu faktor penyebab tidak langsung dari kematian ibu yaitu terlambat mengetahui tanda bahaya kehamilan. Untuk dapat mengantisipasi hal tersebut maka diperlukan suatu upaya untuk dapat mengenali komplikasi kehamilan atau tanda bahaya kehamilan. Salah satunya adalah dengan pemanfaatan buku KIA yang didalamnya berisi informasi tentang tanda bahaya kehamilan, maka ibu dapat bersikap positif dan agar dapat melakukan tindakan yang tepat saat menemui tanda bahaya kehamilan (Suryani, 2009).

Menurut Nurrizka (2013), target AKI Indonesia sesuai MDGs (Millenium Develop-ment Goals) 2015 adalah 102/100.000 kelahiran hidup, dengan posisi 359/100.000 kelahiran hidup pada tahun 2012 maka akan sangat sulit bagi pemerintah untuk mencapai target penurunan AKI 2015. Sedangkan Target AKB Indonesia sesuai MDGs 2015 adalah 23/1.000 kelahiran hidup. Untuk mencapai target tersebut perlu upaya percepatan yang lebih besar dan kerja-sama antara tenaga kesehatan (Oktikasari, 2013).

\section{METODE}

Jenis penelitian ini adalah penelitian observasional yakni dengan hanya mengamati tanpa melakukan perlakuan pada objek penelitian, menurut waktunya adalah cross sectional yakni pengamatan hanya dilakukan pada suatu saat saja. Menurut analisanya merupakan penelitian analitik yaitu mengetahui faktor-faktor pemanfaatan buku KIA terhadap pengetahuan ibu tentang tanda bahaya kehamilan di Wilayah Kerja Puseksmas Matapura 2 Kabupaten Banjar. Jumlah sampel pada penelitin ini berjumlah 83 ibu hamil.
Hasil Dari hasil penelitian ke 83 ibu hamil didapatkan karakteristik responden sebagai berikut:

Tabel 1. Karakteristik Responden

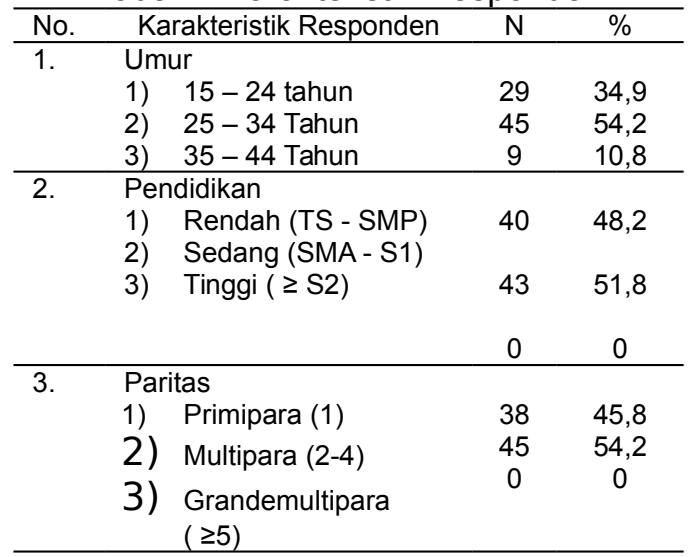

Dari tabel diatas dapat dilihat untuk umur responden terbanyak pada rentang 25 - 34 tahun ada 45 ibu hamil $(54,2 \%)$, untuk tingkat pendidikan sendiri lebih banyak kategori sedang ada $43 \mathrm{ibu}$ hamil $(51,8 \%)$ berpendidikan SMA dan S1 dan untuk kategori paritas didapatkan dari 83 ibu hamil terdapat $52(62,7 \%)$ merupakan kehamilan ke 2 dan ke 3 saat penelitian.

Tabel 2. Distribusi Frekuensi Variabel Pengetahuan Ibu Hamil Tentang Tanda Bahaya Kehamilan, Paritas, dan

Fungsi Pemanfaatan Buku KIA di Wilayah Kerja Puskesmas Martapura 2

\begin{tabular}{|c|c|c|c|}
\hline No. & Variabel Univariat & $\mathrm{N}$ & $\%$ \\
\hline \multirow[t]{3}{*}{1.} & Pengetahuan & & \\
\hline & 1) Baik & 49 & 59 \\
\hline & 2) Kurang Baik & 34 & 41 \\
\hline \multirow[t]{3}{*}{2.} & Paritas & & \\
\hline & 1) Primipara (1) & 38 & 45,8 \\
\hline & 2) Multipara (2-4) & 45 & 54,2 \\
\hline \multirow[t]{3}{*}{3.} & Pencatatan Buku KIA & & \\
\hline & 3) Lengkap & 68 & 81,9 \\
\hline & 4) Tidak Lengkap & 15 & 18,1 \\
\hline \multirow[t]{3}{*}{4.} & Komunikasi Buku KIA & & \\
\hline & 1) Baik & 58 & 69,6 \\
\hline & 2) Kurang Baik & 25 & 30,1 \\
\hline
\end{tabular}

Dari tabel diatas didapatkan 45 ibu $(54,2 \%)$ dengan status Multipara, 49 ibu hamil (59\%) berpengetahuan baik, ada 68 ibu hamil (81,9\%) dengan pencatatan buku KIA yang lengkap, serta 58 ibu hamil (69,6\%) menggunakan buku KIA dengan baik sebagai sarana komunikasi dengan petugas kesehatan.

Tabel 3. Hubungan Paritas dengan Pengetahuan Ibu Hamil Tentang Tanda Bahaya Kehamilan 


\begin{tabular}{|c|c|c|c|c|c|c|c|}
\hline \multirow[t]{2}{*}{ Perit } & \multicolumn{2}{|c|}{$\begin{array}{l}\text { Pengetahuan } \\
\text { Baik }\end{array}$} & \multicolumn{2}{|c|}{$\begin{array}{l}\text { Pengetahuan } \\
\text { Kurang }\end{array}$} & \multicolumn{2}{|c|}{ Total } & $\begin{array}{c}\mathrm{P} \text { Value } \\
(\alpha=0,05)\end{array}$ \\
\hline & $\mathrm{N}$ & $\%$ & $\mathrm{~N}$ & $\%$ & $\mathrm{~N}$ & $\%$ & \\
\hline Primipara & 17 & 44,7 & 21 & 55,3 & 38 & 100 & 0,027 \\
\hline Multipara & 32 & 71,1 & 13 & 28,9 & 45 & 100 & \\
\hline Total & 49 & 59,0 & 34 & 41,0 & 83 & 100 & \\
\hline
\end{tabular}

Hasil uji chi Square didapatkan nilai 0,027 yang artinya $p$ value $<\alpha(0,05)$ sehingga dapat disimpulkan bahwa ada hubungan antara Paritas dengan tingkat Pengetahuan lbu mengenai Tanda Bahaya Kehamilan di Wilayah Kerja Puskesmas Martapura 2 Tahun 2018.

Tabel 4 Hubungan Fungsi Pencatatan Buku KIA dengan Pengetahuan Ibu Hamil Tentang Tanda Bahaya Kehamilan

\begin{tabular}{lccccccc}
\hline $\begin{array}{l}\text { Pencatatan } \\
\text { Buku KIA }\end{array}$ & \multicolumn{2}{c}{$\begin{array}{c}\text { Pengetahuan } \\
\text { Baik }\end{array}$} & \multicolumn{2}{c}{$\begin{array}{c}\text { Pengetahuan } \\
\text { Kurang }\end{array}$} & Total & $\begin{array}{c}\text { P Value } \\
(\alpha=0,05)\end{array}$ \\
\cline { 2 - 7 } & $\mathrm{N}$ & $\%$ & $\mathrm{~N}$ & $\%$ & $\mathrm{~N}$ & $\%$ & \\
\cline { 1 - 7 } Lengkap & 45 & 66,2 & 23 & 33,8 & 68 & 100 & 0,012 \\
\cline { 1 - 5 } $\begin{array}{l}\text { Tidak } \\
\text { Lengkap }\end{array}$ & 4 & 26,7 & 11 & 73,3 & 15 & 100 & \\
\cline { 1 - 5 } Total & 49 & 59,0 & 34 & 41,0 & 83 & 100 & \\
\hline
\end{tabular}

Hasil uji chi Square didapatkan nilai 0,012 yang artinya $p$ value $<\alpha(0,05)$ sehingga dapat disimpulkan bahwa ada hubungan antara fungsi Pencatatan Buku KIA dengan tingkat Pengetahuan Ibu mengenai Tanda Bahaya Kehamilan di Wilayah Kerja Puskesmas Martapura 2 Tahun 2018.

Tabel 4 Hubungan Fungsi Komunikasi Buku KIA dengan Pengetahuan Ibu Hamil Tentang Tanda Bahaya Kehamilan

\begin{tabular}{lccccccc}
\hline \multirow{2}{*}{$\begin{array}{l}\text { Komunikasi } \\
\text { Buku KIA }\end{array}$} & \multicolumn{2}{c}{$\begin{array}{c}\text { Pengetahuan } \\
\text { Baik }\end{array}$} & \multicolumn{2}{c}{$\begin{array}{c}\text { Pengetahuan } \\
\text { Kurang }\end{array}$} & Total & $\begin{array}{c}\text { P Value } \\
(\alpha=0,05)\end{array}$ \\
\cline { 2 - 7 } & $\mathrm{N}$ & $\%$ & $\mathrm{~N}$ & $\%$ & $\mathrm{~N}$ & $\%$ & \\
\cline { 2 - 8 } Baik & 39 & 67,2 & 19 & 32,8 & 58 & 100 & 0,038 \\
\hline Kurang & 10 & 40,0 & 15 & 60,0 & 25 & 100 & \\
\hline Total & 49 & 59,0 & 34 & 41,0 & 83 & 100 & \\
\hline
\end{tabular}

Hasil uji chi Square didapatkan nilai 0,038 dimana $p$ value $<\alpha(0,05)$ yang berarti bahwa ada hubungan antara fungsi Komunikasi Buku KIA dengan tingkat Pengetahuan Ibu mengenai Tanda Bahaya Kehamilan di Wilayah Kerja Puskesmas Martapura 2 Tahun 2018.

\section{Pembahasan}

Berdasarkan Hasil Penelitian diketahui bahwa kebanyakan responden berstatus multipara, yang artinya para ibu hamil tersebut telah mengalami dua kali kehamilan atau lebih dengan janin mampu mencapai titik hidup. Hasil Uji chi Square terkait variabel penelitian tentang Paritas dengan Pengetahuan lbu Hamil didapatkan nilai 0,027 yang artinya $p$ value $<\alpha$ $(0,05)$ sehingga dapat disimpulkan bahwa terdapat hubungan antara Paritas dengan Pengetahuan lbu mengenai Tanda Bahaya Kehamilan. Dari itu dapat dikatakan bahwa semakin sering seorang ibu melahirkan bayi dengan selamat, maka semakin baik juga tingkat pengetahuannya tentang tanda bahaya kehamilan. Menurut Notoadmodjo (2007) pengetahuan sangat erat hubungannya dengan paritas karena semakin sering seseorang wanita melahirkan semakin banyak pengalaman pribadi yang diperoleh dan dapat menuntun seseorang dalam menarik kesimpulan. Penelitian ini sejalan dengan hasil penelitian Astuti (2011) yang menyatakan bahwa ada hubungan antara paritas ibu dengan tingkat pengetahuan tentang tanda bahaya pada kehamilan dengan $p$ value 0,040 .

Dalam penelitian ini yang dimaksud dengan informasi adalah fungsi pencatatan yang terdapat pada buku KIA, dimana semakin lengkap pencatatan yang dilakukan oleh petugas dapat memiliki hubungan dengan tingkat pengetahuan responden ke arah yang lebih baik dan informatif. Penelitian ini sejalan dengan Sistiarani, dkk (2016) tentang Hubungan Fungsi Pemanfaatan Buku KIA terhadap Pengetahuan Kesehatan Ibu dan Anak pada Ibu,dimanadari hasil penelitiannyadiketahui bahwa dari 40 responden terdapat 23 orang $(45,1 \%)$ yang memiliki fungsi pencatatan buku KIA dengan kategori lengkap dan tingkat pengetahuannya baik. Hasil uji statistik Chi Square-nya menunjukkan $p$ value $=0,012$ sehingga terdapat hubungan antara fungsi Pencatatan Buku KIA dengan tingkat Pengetahuan Ibu di wilayah kerja Puskesmas Ajibarang I Kabupaten Banyumas. Hasil serupa juga ditunjukkan oleh Hanifah (2013) yang meneliti tentang Hubungan Kepemilikan Buku KIA dengan Pengetahuan dan Sikap Ibu Hamil, dimana hasilnya menyebutkan bahwa ada hubungan antara kepemilikan buku KIA dengan pengetahuan ibu hamil di Puskesmas Fatukanutu Kabupaten Kupang.

Menurut asumsi peneliti kecenderungan seseorang untuk memanfaatkan buku KIA khususnya ditinjau dari fungsi pencatatannya, dapat meningkatkan pengetahuan mengenai tanda bahaya kehamilan. Dengan memiliki pengetahuan yang baik, seorang ibu akan dapat melakukan deteksi dini pada dirinya sendiri ketika mengalami masalah dari risiko bahaya kehamilan yang bisa terjadi.Pemanfaatan fungsi pencatatan buku KIA yang lengkap pada ibu hamil di Wilayah Kerja Puskesmas Martapura 2 tidak lepas dari peran petugas kesehatan yang selalu menjalankan pekerjaannya sesuai dengan prosedur yang ditetapkan, serta adanya kemampuan yang baik dari para petugas di 
lapangan dalam melakukan pencatatan yang lengkap pada buku KIA sehingga hasilnya menunjukkan hal yang positif bagi pengetahuan ibu tentang bahaya yang dapat terjadi pada masa kehamilan.

Hasil uji chi Square didapatkan nilai 0,038 dimana $p$ value $<\alpha(0,05)$ yang berarti bahwa ada hubungan antara fungsi Komunikasi Buku KIA dengan tingkat Pengetahuan Ibu mengenai Tanda Bahaya Kehamilan di Wilayah Kerja Puskesmas Martapura 2. Buku KIA diarahkan untuk meningkatkan pengetahuan dan pemahaman masyarakat tentang kesehatan ibu dan anak.Buku KIA selain sebagai catatan kesehatan ibu dan anak, alat monitor kesehatan dan alat komunikasi antara tenaga kesehatan dengan pasien (Hasanbasri dan Ernoviana, 2007). Penelitian ini sesuai dengan hasil penelitian Khuzaiyah, dkk (2018) yang menggambarkan bahwa banyak responden $(30,2 \%)$ yang berada di wilayah puskesmas Kabupaten Pekalongan selalu memanfaatkan buku KIA sebagai media untuk bertanya kepada petugas kesehatan. Begitu pula dengan penelitian Hanifah (2013) dimana hasilnya menyebutkan bahwa ada hubungan antara kepemilikan buku KIA dengan pengetahuan ibu hamil

\section{KESIMPULAN}

Dari 83 responden yang diteliti didapatkan 45 ibu $(54,2 \%)$ dengan status Multipara, 49 ibu hamil (59\%) berpengetahuan baik, ada 68 ibu hamil $(81,9 \%)$ dengan pencatatan buku KIA yang lengkap, serta 58 ibu hamil $(69,6 \%)$ menggunakan buku KIA dengan baik sebagai sarana komunikasi dengan petugas kesehatan. Terdapat hubungan antara Paritas dengan tingkat Pengetahuan Ibu mengenai Tanda Bahaya Kehamilan dengan $p$ value 0,027 . Variabel fungsi pencatatan buku KIA berhubungan dengan pengetahuan ibu hamil $(p=0,012)$ serta variabel fungsi komunikasi buku KIA berhubungan dengan pengetahuan ibu hamil $(p=0,038)$.

\section{Saran}

Bagi pihak Puskesmas agar dapat meningkatkan fungsi pemanfaatan buku KIA dengan membuat kebijakan untuk ibu hamil diwajibkan membaca buku KIA sebelum mendapatkan pelayanan ANC untuk meningkatkan pengetahuan terutama mengenai tanda bahaya selama kehamilan. Referensi bagi peneliti lain untuk menggunakan variabel lain yang belum diteliti seperti dukungan suami dan kader posyandu.

\section{DAFTAR PUSTAKA}

Astuti, Hutari Puji, 2011. Hubungan Karakteristik Ibu Hamil dengan Tingkat Pengetahuan Tentang Tanda Bahaya Pada Kehamilan di Puskesmas Sidoharjo Kabupaten Sragen. Jurnal Kesehatan Kusuma Husada Vol 3 No. 2, Juli 2012. ISSN 20875002

Budiman \& Riyanto A. 2013. Kapita Selekta Kuisioner Pengetahuan dan Sikap dalam Penelitian Kesehatan.Jakarta : Salemba Medika pp 66-69

Departemen Kesehatan Republik Indonesia, 2009. Pedoman Umum Manajemen Penerapan Buku KIA Departemen Kesehatan Republik Indonesia ; Jakarta

Dinas Kesehatan Kabupaten Banjar, 2017. Laporan Tahunan 2017, Kabupaten Banjar

Hanifah, Astin Nur., 2013. Hubungan Kepemilikan Buku KIA Dengan Pengetahuan dan Sikap Ibu hamil Tentang Perawatan Kehamilan di Puskesmas Fatukanuntu Kabupaten Kupang Tahun 2013. Jurnal Poltekes Kupang

Hasanbasri M. dan Ernoviana. 2007. Implementasi buku kesehatan ibu dan anak di Kabupaten Mimika Papua. [e-journal] working Paper Series No 16 April 2007. Yogyakarta : Program Magister Kebijakan dan Manajemen Pelayanan Kesehatan Universitas Gadjah Mada

Kemenkes RI. 2004. Keputusan MenteriKesehatan Republik Indonesia Nomor 284/Menkes/SK/III/2004 tentang Buku Kesehatan Ibu dan Anak (KIA). Hal :1-2.

Kemenkes RI. 2011. Buku Kesehatan Ibu dan Anak.Jakarta: Kemenkes dan JICA. Hal:i, : iv-48.

Khuzaiyah, Siti., Milatun Khanifah., Nur Chabibah., 2018. Evaluasi Pencatatan dan Pemanfaatan Buku Kesehatan Ibu dan Anak (KIA) Oleh bldan, Ibu dan Keluarga. Indonesian Journal of Nursing Practices, Vol. 2 No. 1, Juni 2018. ISSN 25484249

Notoadmodjo, S. 2005. Metodelogi Penelitian Kesehatan. Jakarta : Rinke Cipta.

Notoatmodjo, S. 2007. Pendidikan dan Perilaku Kesehatan, Rineka Cipta : Jakarta

Nursalam.2003. Konsep dan Penerapan Metodelogi Penelitian IImu keperawatan : Pedoman Skripsi, Tesis dan Instrumin Penelitian. Jakarta : Slemba Medika.

Nurrizka, HR. 2013. Arah dan Strategi KebijakanPenurunan Angka Kematian Ibu (AKI), Angka Kematian Bayi (AKB) dan Angka Kematian Balita (AKABA) di Indonesia.Jakarta Prakarsa Policy Update. 
Hal:9

http://theprakarsa.org/new/ck uploads/files/P OLICY\%20UPDATE\%20KIA CY.pdf.

Oktikasari, D. 2013. Asuhan Kebidanan BayiBaru Lahir pada Bayi Ny. B dengan Asfiksia Ringan di RSUD Dr. Moewardi Surakarta tahun 2013. Hal:1. Stikes Kusuma Husada Surakarta.

Oktaria, C., Elvira,G.,Dyah, U. 2013. Hubungan Pengetahuan, Sikap, Kepatuhan Ibu Hamil dan Ibu Bayi dalam Penggunaan Buku KIA di Puskesmas Geger Bangkalan jawa Timur

Sistiarani, Colti., Elviera Gamelia., Dyah Umiyarni P.S., 2014. Fungsi Pemanfaatan Buku KIA terhadap Pengetahuan Kesehatan Ibu dan Anak pada Ibu. Jurnal Kesehatan Masyarakat Nasional, Vol. 8, No. 8, Mei 2014.

Suryani, WS. 2009. Hubungan Pengetahuan tentang Tanda Bahaya Kehamilan dan Sikap Ibu Hamil di RB Perwita Sari Klaten.KTI. DIV Kebidanan Fakultas Kedokteran Universitas Sebelas Maret 